\title{
autêntica
}

\author{
ARTIGOS
}

\section{RAZÕES E EXPECTATIVAS DA ESCOLHA PROFISSIONAL DOCENTE: O CURSO DE PEDAGOGIA EM FOCO}

Mônica Patrícia da Silva Sales

Wilson Rufino da Silva

\begin{abstract}
RESUMO: Este artigo tem por objetivo analisar as razões e as expectativas dos estudantes de Pedagogia em relação à escolha pela profissão docente. Trata-se de um estudo de natureza qualitativa, no qual buscamos fazer uma análise da realidade contextual a partir de uma aproximação com o fenômeno investigado e com o universo conceitual dos sujeitos. Elegemos como campo empírico de pesquisa uma instituição privada. Participaram deste estudo 153 estudantes do curso de Pedagogia situados em diferentes estágios da formação, que responderam a um questionário com base em questões abertas e fechadas. Para análise dos dados, buscamos respaldo na técnica de análise de conteúdo de Bardin (2010). Os dados revelaram que a escolha do curso se deu em função da identificação com crianças e com a função social da profissão, da busca por aperfeiçoamento profissional, do amplo horizonte do mercado de trabalho e da possibilidade de empregabilidade. A maioria dos/as estudantes pretende atuar ou continuar atuando na docência e possui expectativas muito positivas em relação ao seu exercício profissional.
\end{abstract}

PALAVRAS-CHAVE: Profissão docente; Pedagogia; Escolha profissional.

\section{ABSTRACT}

This article aims to analyze the reasons and expectations of Pedagogy students regarding the choice for the teaching profession. It is a qualitative study in which we seek to analyze the contextual reality from an approach to the investigated phenomenon and the conceptual universe of subjects. Elected as empirical field research a private institution. The study included 153 students of the Faculty of Education located at different stages of training, who responded to a questionnaire that was structured on the basis of open and closed questions. For data analysis we seek to support the content analysis technique based on Bardin (2010). The data revealed that the choice of course was due to the identification of children and the social role of the profession, the search for professional development, the broad horizon of the labor market and the possibility of employability. Most of the students intend to work or continue working in teaching and have very positive expectations in relation to their professional practice.

KEYWORDS: Teaching profession; Pedagogy; Professional choice. 


\section{autêntica}

\section{INTRODUÇÃO}

Neste estudo buscamos discutir a formação de professores a partir da reflexão sobre a profissão, entendendo ser esse um campo de tensão e conflitos que se inscrevem nas subjetividades dos sujeitos e em contextos sociais mais amplos. Para tanto, procuramos analisar as razões e as expectativas da escolha profissional docente de estudantes do curso de Pedagogia de uma instituição privada localizada no agreste de Pernambuco.

Este artigo é fruto das discussões travadas na disciplina Estudos Avançados em Formação de Professores e Prática Pedagógica do Programa de Pós-Graduação em Educação da Universidade Federal de Pernambuco, ministrada pela professora doutora Maria Eliete Santiago. As políticas e as práticas curriculares na formação de professores e a atratividade da profissão foram os eixos que nortearam as discussões ao longo do curso. Todavia, para a produção deste artigo a questão da atratividade da profissão docente nos inquietou e nos mobilizou a pesquisar, uma vez que, como mostrou Gatti (2009), a profissão docente vem deixando de ser uma opção profissional procurada pelos(as) jovens.

Sabemos que, no processo de escolha profissional, muitos são os fatores a considerar, como a realização pessoal, a identificação pessoal e profissional, a remuneração, a carreira, o prestígio e o reconhecimento social, entre outros. Esses fatores são determinantes e determinados pelas experiências individuais de cada um/a, e fazem parte de uma construção socio-histórica, cultural e política da sociedade na qual se está inserido. Desse modo, pressupomos que a maneira como as profissões são representadas no imaginário social das pessoas e disseminadas nos meios de comunicação influenciam as escolhas profissionais dos jovens.

Conforme Dubar (2006), a noção de trabalho analisada no atual contexto está em plena transformação. O trabalho, não importa qual, tornou-se um desafio para o reconhecimento de si, um tempo de incerteza e grande implicação social, que tem exigido um investimento pessoal cada vez maior.

Nesse contexto, a escolha pela profissão se situa como um momento de tensões, pois o que se coloca em jogo é um projeto de futuro. E, nesse caso, não é fácil realizar tal escolha. Junta-se a isso o fato de, na maioria das vezes, serem jovens adolescentes cheios de dúvidas e conflitos, o que agrava ainda mais o quadro situacional. Muitos jovens vão em busca da profissão que lhes proporcionem maior rentabilidade e uma situação mais estável. Além disso, eles procuram por profissões que estão em ascensão ou que possuem uma tradição de prestigio e valorização social. As mudanças constantes na sociedade fazem com que muitas profissões surjam e outras desapareçam.

Nesse sentido, discutir atividade docente na contemporaneidade requer que consideremos os desafios que se colocam para essa profissão, como a questão da atratividade, da carreira, da permanência de bons/boas professores/as na sala de aula e da qualidade social do trabalho desenvolvido pelos/as docentes. Especial atenção deve ser dada à atratividade da profissão, tendo em vista o que apontam as pesquisas recentes na área, como a realizada em 2009 pela Fundação Victor Civita (FVC) em parceria com a Fundação Carlos Chagas (FCC). Essa pesquisa revelou que apenas $2 \%$ dos jovens que frequentam o $3^{\circ}$ ano do ensino médio pretendem cursar Pedagogia ou alguma licenciatura. No estudo foram ouvidos 1.501 alunos em 18 escolas públicas e particulares de 8cidades (GATTI, 2009). Tais dados são reveladores da falta de prestígio social e de valorização da profissão docente na sociedade.

Conforme apontam Tardif e Lessard (2009), a docência é uma das mais antigas ocupações modernas, tão antiga quanto a medicina e o direito, porém, quando situada dentro da organização socioeconômica do 


\section{autêntica}

trabalho, ela representa atualmente um setor nevrálgico, pois não tem se constituído como uma profissão atrativa e valorizada.

Diante das questões aqui discutidas, inquieta-nos compreender: quais razões levaram os/as estudantes a escolher o curso de Pedagogia? Quais suas expectativas em relação à profissão docente? Qual o perfil desses estudantes?

Este trabalho se inscreve em uma abordagem de natureza qualitativa através da qual buscamos fazer uma análise da realidade contextual a partir de uma aproximação com o fenômeno investigado e com o universo conceitual dos sujeitos (MINAYO, 2007). Elegemos como campo empírico de pesquisa uma instituição privada, a Faculdade de Filosofia, Ciências e Letras de Caruaru, considerando a sua trajetória histórica de mais de 50 anos formando professores e o seu pioneirismo na região agreste de Pernambuco, assim como sua atuação no ensino, na pesquisa e na extensão, algo não comum em instituições privadas. É importante pontuar que as instituições privadas são as que mais formam professores/as (SILVA, 2007), portanto, trata-se de um campo que merece ser pesquisado. Participaram deste estudo 153 estudantes do curso de Pedagogia, situados em diferentes estágios formativos, que aderiram voluntariamente à pesquisa.

Utilizamos como instrumento de coleta de dados o questionário, entendido como interlocução planejada (CHIZZOTTI, 1991), com base em questões objetivas e subjetivas com a finalidade de traçar o perfil dos/as estudantes e compreender suas razões e expectativas em relação à profissão e ao exercício profissional. Para a análise dos dados, buscamos respaldo na técnica de análise de conteúdo temática de Bardin (2010), que procura identificar o conteúdo manifesto e latente na produção dos sujeitos, permitindo organizar categorias ou subcategorias que nos ajudam a realizar inferências e não somente constatações, contemplando as condições contextuais de sua produção.

A análise dos dados segundo os critérios estabelecidos por Bardin (2010) consiste em pré-análise, exploração do material e tratamento dos dados. Seguindo esses passos, procuramos organizar um plano de análise, definindo o tempo e o cronograma da pesquisa, e procedemos com a revisão teórica de estudos e pesquisas que discutiam a temática em questão. Selecionado os referenciais teóricos e as pesquisas, realizamos a leitura do material e formulamos os pressupostos e os objetivos. Na medida em que lemos, analiticamente, as fontes escolhidas, questionamos e revisamos os pontos de partida tomados na pesquisa. A exploração do conteúdo dos questionários nos permitiu tratar e interpretar os dados tornando-os significativos e válidos através da organização, codificação e categorização das unidades em torno de temas e características que emergiram do conteúdo. Esse tratamento dos dados nos possibilitou identificar os elementos que expressavam as razões e as expectativas de estudantes de Pedagogia em relação ao curso e à profissão.

Na organização das variáveis, lançamos mão do software SPSS, sigla representativa do Statistical Package for the Social Sciences, um pacote estatístico para as ciências sociais utilizado mediante um software aplicativo que permite a tabulação de dados em grande quantidade e diversificação. As planilhas do SPSS foram alimentadas com os dados colhidos pelos questionários distribuídos entre os/as discentes de Pedagogia.

Organizamos, então, o texto em três partes. Num primeiro momento situamos a profissão docente em seus dilemas contemporâneos. Em seguida, trouxemos elementos dos debates e embates que envolvem o curso de Pedagogia, situando também a formação do/a pedagogo/a na FAFICA, campo de investigação desta pesquisa. Na terceira parte, consideramos e analisamos as razões e as expectativas pela escolha da 


\section{autêntica}

profissão docente e pelo curso de Pedagogia, caracterizando, inicialmente, o perfil dos/as licenciandos/as de Pedagogia da instituição pesquisada.

\section{PROFISSÃO DOCENTE: DILEMAS CONTEMPORÂNEOS}

A profissão docente pode ser estudada por diferentes abordagens que destacam a formação inicial ou continuada dos/as professores/as, a prática pedagógica, a didática, o processo de ensino e aprendizagem, as políticas públicas, as condições de trabalho, os saberes necessários à docência, a ambiência docente, a profissionalização docente, entre outras. Essa multiplicidade de abordagens nos permite afirmar que esse é um campo fértil e em constante expansão. Mas, neste trabalho, interessa-nos compreender as razões e as expectativas de estudantes do curso de Pedagogia em relação à profissão docente, por entendermos que esses dados são reveladores de definições e sentidos atribuídos à docência, bem como dos valores sociais, culturais, históricos e normativos da sociedade.

O termo "profissão" vem do latim professio, que significa declaração, exercício, ocupação e emprego. Para Popkewitz (1995, p.38), profissão é "uma palavra de construção social, cujo conceito muda em função das condições sociais em que as pessoas a utilizam." Esse termo, portanto, estabelece uma diferenciação entre oficio ou ocupação, pois pressupõe a identificação de um grupo altamente formado, competente e especializado.

Segundo Veiga, Araújo e Kapuziniak (2005), a profissão docente se configura como uma das mais antigas ocupações, datada do final do século XVII, quando a formação docente foi institucionalizada na Europa. Na época, alguns estudiosos, como Lutero, Erasmo e Comênio, defendiam uma formação especializada que delineasse um perfil de educador/a que pudesse levar ensinamentos aos/às jovens, sendo a primeira experiência de formação de professores/as de responsabilidade de Charles Démia (1637-1689), um abade francês. Já no final do século XVII, Jean Baptiste de La Salle (1651-1719), também francês, funda a congregação dos Lassalistas, que institui, em 1688, uma escola de formação de professores/as. Em 1974, J. Lakanal (17621845) propõe o estabelecimento de escolas normais na França.

Em 1968, a tendência à massificação da educação superior já vigente em outros países chega ao Brasil, provocando a expansão e o aumento indiscriminado de instituições e matrículas, sem com isso assegurar a redemocratização do acesso com garantia de permanência e qualidade. A expansão da educação superior em nosso país desde então é constante, especialmente no que se refere ao setor privado, que possui o maior número de instituições (88\% do número total) segundo dados do Censo 2011 (INEP, 2013). Assim, esse setor é o que mais forma professores/as no país.

No que se refere à valorização dos profissionais da educação, verificamos na legislação do país que a Constituição Brasileira de 1988, em seu art. 206, parágrafo V, já mencionava como princípio constitucional a "valorização dos profissionais do ensino, garantidos, na forma da lei, planos de carreira para o magistério público, com piso salarial profissional e ingresso exclusivamente por concurso público de provas e títulos" (BRASIL, 1988), resultado de uma tentativa de reconhecimento do/a professor/a como categoria profissional especializada. Mas poucos foram os avanços alcançados no sentido de valorização da categoria docente.

Nóvoa (1991, p. 27) entende que "o estatuto social e econômico é a chave para o estudo dos professores e da sua profissão". Reconhecemos que o nível de ensino no qual o docente atua implica em seu estatuto social e econômico, como é o caso da docência no ensino superior, que possui certo prestígio social quando comparada à docência na educação básica. 


\section{autêntica}

Ainda conforme Nóvoa (1991, p.12), a preocupação com a formação é secular, porém as iniciativas de formação não garantiram à docência o estatuto de profissão. Isso ocorre porque, "inicialmente, a função docente desenvolveu-se de forma subsidiária e não especializada, constituindo uma ocupação secundária de religiosos ou leigos das mais diversas origens." Portanto, a gênese da profissão docente tem lugar no seio de congregações religiosas, através do trabalho de ensino desenvolvido pela Igreja e posteriormente realizado por leigos, o que provocou um entendimento de docência articulado à vocação e ao sacerdócio. Contudo, a visão sacerdotal de docência vem aos poucos dando espaço a uma visão profissional.

Para Tardif e Lessard (2009, p.17), a falta de um estatuto de profissão para a docência deve-se ao fato de que

[...] fundamentalmente o ensino é visto como uma ocupação secundária ou periférica em relação ao trabalho material e produtivo. A docência e seus agentes ficam nisso subordinados à esfera da produção, porque sua missão primeira é preparar os filhos dos trabalhadores para o mercado de trabalho.

Diferentemente de outras áreas que trabalham com matéria-prima, a educação tem como sujeito de trabalho o ser humano, que na relação se constrói, se modifica e se transforma. Por sua vez, essa relação não é uma relação passiva, mas essencialmente ativa, em que ambos, professor/a e aluno/a, são sujeitos do processo, pois, conforme Freire (1996), "não há docência sem discência".

A supervalorização das atividades produtivas em detrimento das atividades intelectuais vem sendo modificada pela sociedade, pois os agentes sociais, ou seja, os trabalhadores que lidam com seres humanos, constituem hoje uma das principais peças da economia das sociedades modernas, além de representarem a principal carga econômica para o Estado (TARDIF; LESSARD, 2009). Diante da atual conjuntura da sociedade, percebemos avanços em reconhecer a especificidade epistemológica da profissão docente e seu relevante papel social.

Nessa perspectiva, reconhecemos a importante função dos movimentos sociais da categoria profissional, que colaboraram para estimular a realização de estudos sobre a docência, o que tem contribuído para ampliação dos nossos conhecimentos sobre as particularidades que revestem relações históricas, teórico-metodológicas, socioculturais, políticas e subjetivas dessa profissão, ratificando a importância de seu reconhecimento profissional e social.

Mesmo diante desses avanços, reconhecemos que o campo da profissionalização docente merece ser explorado e demanda muitas conquistas para sua legitimação. Segundo Batista Neto (2006), a valorização do magistério e a visão do/a docente como profissional do ensino depende do enfrentamento de alguns desafios, a saber: desenvolvimento de políticas de financiamento, implantação do piso nacional de salário dos professores, melhoria nas condições gerais de trabalho, políticas de formação inicial e continuada, reforma curricular dos cursos de formação, fiscalização e controle social do acesso ao magistério e um código de ética profissional.

Corroborando com as reflexões do autor, entendemos que a superação desses desafios contribui para o processo de profissionalização docente que, dessa forma, compreende o envolvimento da categoria docente na busca pela valorização da profissão através de condições de acesso, formação e carreira no magistério. Nesses termos, a profissionalização é um processo de luta e conquista que envolve interesses do entorno dos profissionais, mas, sobretudo, abrange os interesses sociais mais amplos, uma vez que a profissão docente é uma prática social (SANTIAGO, 2006). 


\section{autêntica}

Para nós, a necessidade de discutir e de fortalecer os processos de profissionalização indica que ainda há fragilidades nas ações de valorização da categoria que precisam ser superadas. Essa superação deve partir do próprio movimento docente, uma vez que as políticas públicas nem sempre a priorizam e, ainda, quando o fazem, muitas vezes a distorcem pelo poder executivo e também pelas gestões das instituições.

\section{DEBATES E EMBATES NO ÂMBITO DO CURSO DE PEDAGOGIA}

Passados mais de 70 anos desde a sua criação em 1939, o curso de Pedagogia vem sendo alvo de debates e embates que trazem as marcas, por um lado, dos contextos socioeconômicos, políticos e culturais de cada momento histórico, e, por outro, das políticas educacionais, particularmente o aparato legal que incide sobre os objetivos, a estrutura e o funcionamento do curso.

Em seus primórdios e em boa parte de sua trajetória, o curso de Pedagogia vinculou-se estritamente como a continuidade natural do Curso Normal, sendo a ênfase na teoria o balizador da formação do/a pedagogo/a. Segundo Cruz (2009, p. 1.192),

[...] mesmo o Curso de Pedagogia tendo como uma de suas incumbências a formação de professores para a Escola Normal, além do curso ginasial, a parte referente à formação de professores foi pouco investida, recaindo o peso maior nas discussões teóricas sobre educação.

A densidade teórica na formação do/a pedagogo/a é compreensível à medida que se entende que esse/a profissional é incumbido de teorizar sobre o fato educativo. Outrossim, o/a pedagogo/a não só se identifica, enquanto ação profissional, com a teorização da prática educativa, como também com o seu exercício (SAVIANI, 2007). Assim, a relação dialética entre teoria e prática é de tal modo constituinte da pedagogia que podemos falar do pedagogo como profissional prático-teórico.

Com o Parecer CNE n. ${ }^{\circ}$ 252, de 1969, e a institucionalização das habilitações no curso de Pedagogia, acentua-se a dicotomia teórico-prática pela tendência tecnicista e a fragmentação na divisão do trabalho escolar presente na formação do/a pedagogo/a especialista na orientação educacional, na administração escolar, na supervisão e na inspeção de unidades escolares e de sistemas de ensino (CRUZ, 2009).

Os/as educadores/as e suas entidades representativas, entre elas a Associação Nacional pela Formação dos Profissionais em Educação (ANFOPE), defendem uma proposta de formação docente crítico-transformadora, constituída em pilastras como: a indissociabilidade entre teoria/prática; o entendimento da ação docente como uma prática coletiva, social e contextualizada; a compreensão de que a formação docente é uma tarefa inerentemente política, constituída de saberes plurais; a docência, como atividade profissional, sendo base do processo formativo.

Esses elementos defendidos pelo movimento dos educadores acabaram por influenciar a Resolução n. ${ }^{\circ} 1$ do CNE/CP, de 15 de maio de 2006, que versa sobre as Diretrizes Curriculares Nacionais (DCNs) para o curso de graduação em Pedagogia. Em seu artigo $2^{\circ}$, afirma-se:

As Diretrizes Curriculares para o curso de Pedagogia aplicam-se à formação inicial para o exercício da docência na Educação Infantil e nos anos iniciais do Ensino Fundamental, nos cursos de Ensino Médio, na modalidade Normal, e em cursos de Educação Profissional na área de serviços e apoio escolar, bem como em outras áreas nas quais sejam previstos conhecimentos pedagógicos (BRASIL, 2006). 


\section{autêntica}

Percebe-se o leque de possibilidades de formação e atuação que o curso de Pedagogia enseja, tendo a docência como base do processo formativo, entendida como

[...] ação educativa e processo pedagógico metódico e intencional, construído em relações sociais, étnico-raciais e produtivas, as quais influenciam conceitos, princípios e objetivos da Pedagogia, desenvolvendo-se na articulação entre conhecimentos científicos e culturais, valores éticos e estéticos inerentes a processos de aprendizagem, de socialização e de construção do conhecimento, no âmbito do diálogo entre diferentes visões de mundo (BRASIL, 2006, § 1%.

Para Cruz (2009, p. 1.198), ao se debruçar sobre as falas dos "pedagogos primordiais", aqueles/as que estiveram nos primórdios do curso de Pedagogia e que se mantiveram atuantes e influentes na área, o "problema das diretrizes curriculares não está na docência ser ou não o fundamento principal do curso, mas no afastamento do estudo da própria pedagogia". Já Mandú e Aguiar (2013) entendem que o curso de Pedagogia, a partir das DCNs, articula-se em três grandes eixos -a docência, a gestão e a produção de conhecimento, sendo em que a docência, compreendida em sentido ampliado, conforme o artigo $2^{\circ}$ citado acima, englobaria as outras duas dimensões. Ferreira (2006), a seu turno, discute a gestão da educação, em vista do compromisso e responsabilidade na formação para a cidadania, como o gérmen do processo formativo do pedagogo presente nas DCNs. Argumenta que a gestão, fazendo-se em ação na sala de aula, contém

[...] "em gérmen" o espírito e o conteúdo do projeto político pedagógico que expressa o compromisso e o norte da escola por meio da gestão do ensino, da gestão de classe, da gestão das relações, da gestão do processo de aquisição do conhecimento [...] (FERREIRA, 2006, p. 1.348).

Basílio (2013, p. 60), por sua vez, afirma que "existe uma preocupação entre os professores formadores desse Curso [Pedagogia], pois o 'grande leque' que se abre nessa formação poderá causar um esvaziamento na procura pela atuação na sala de aula".

Depreende-se dessas discussões provocadas pelas DCNs (BRASIL, 2006) o quanto o curso de Pedagogia se constituiu e se constitui como alvo de debates e embates.

Nesse contexto de disputas político-pedagógicas em torno da identidade do curso de Pedagogia, Silva (2007) aponta dois modelos: o emancipador, defendido pelo movimento dos educadores, com destaque para a Associação Nacional pela Formação dos Profissionais da Educação (ANFOPE), e o instrumentalista, gestado sob a tutela dos organismos internacionais e implementado pelo MEC/CNE através de suas políticas educacionais.

Enquanto o primeiro, emancipador, "está alicerçado nas ideias de emancipação humana e de construção de uma sociedade radicalmente democrática [...]", o segundo "está fundado na ideia de adequação da educação aos imperativos do ideário de sociedade de mercado, por isso tem como base epistemológica a racionalidade cognitivo-instrumental" (SILVA, 2007, p. 16-17).

Esse cenário de disputas e de consequentes identidades que assume o curso de Pedagogia acaba por influenciar as escolhas, como perspectiva formativa profissional, que as pessoas fazem por essa formação. Dessa forma, tais escolhas são carregadas de razões diversas. Ademais, há um universo de expectativas quanto às possibilidades que o curso abre, como veremos adiante. 


\section{autêntica}

\subsection{A FORMAÇÃO DO/A PEDAGOGO/A NA FAFICA NOS EMBATES E DEBATES DO CURSO DE PEDAGOGIA}

A Faculdade de Filosofia, Ciências e Letras de Caruaru (FAFICA) está inserida no contexto geoeducacional do interior de Pernambuco e foi fundada por sua mantenedora, a Diocese de Caruaru, através da Portaria da Cúria Diocesana n. ${ }^{\circ} 268$, de 9 de agosto de 1960. A FAFICA teve seu funcionamento autorizado, oferecendo na época os cursos de licenciaturas em Letras, Ciências Sociais, História e Pedagogia, pelo Decreto Presidencial n. ${ }^{\circ}$ 50.448, de 12 de abril de 1961, sendo reconhecida, como também seus cursos, em 15 de janeiro de1969, através do Decreto n. ${ }^{\circ} 63.990$ do Conselho Federal de Educação.

No que diz respeito particularmente ao curso de Pedagogia, podemos observar que sua trajetória histórica se confunde com a história da própria FAFICA, que há mais de 50 anos atua na formação de profissionais no campo educacional.

Nessa trajetória de mais de cinco décadas, o curso vem sofrendo reformulações no bojo das controvérsias e determinações legais que envolvem a formação do/a pedagogo/a. Inicialmente, o curso de Pedagogia foi oferecido com duração de quatro anos e com as habilitações em administração escolar, supervisão pedagógica e orientação educacional.

Com a aprovação da Lei n. ${ }^{\circ}$ 9.394, de 20 de dezembro de 1996, a legislação que a seguiu e, ainda, "as proposições da ANFOPE que condensavam a discussão nacional produzidas no movimento dos/as profissionais em educação [...] [e] a própria demanda local oriunda dos interesses da comunidade interna da Faculdade" (SILVA, 2007, p. 223), no ano 2004

[...] foi implantada uma nova estrutura curricular, fruto do trabalho coletivo dos(as) professores(as) do curso que demandou um longo processo de discussão e maturação, considerando a nova realidade social e educacional, mas também atendendo a requerimentos legais oficiais (FAFICA, 2007, p. 3).

Nesse processo de reformulação do curso, foram extintas as habilitações, e a formação do pedagogo passou a ser oferecida num formato único, com o objetivo de formar para a docência nas disciplinas pedagógicas do normal médio e para atuação na gestão escolar.

Pouco tempo depois, novamente atendendo ao que dispõe o Despacho do Diretor do Departamento de Supervisão do Ensino Superior, de 06 de julho de 2006, considerando ainda a Resolução CNE/CP n 01/2006 que institui as Diretrizes Curriculares Nacionais para o curso de Graduação em Pedagogia, licenciatura, os(as) professores(as) do curso de Pedagogia da FAFICA, novamente após estudos, reflexões e discussões reformularam o curso em função das novas prerrogativas que the foram atribuídas. Após aprovação pelo Colegiado de Cursos da Instituição, o curso passou a considerar a docência como fundamento da formação, a ser exercida na Educação Infantil, nos anos iniciais do Ensino Fundamental, no Ensino Médio na modalidade Normal e enfocando, ao longo do curso, conteúdos de gestão (FAFICA, 2007, p. 4).

Entrando na segunda década do século XXI, está em processo de implantação uma nova reformulação, fruto da reflexão em torno das novas demandas locais no que diz respeito ao cenário geoeducacional e às amplas possibilidades de formação que a Resolução CNE/CP n. ${ }^{\circ}$ 01/2006 ensejam. Assim, o curso de Pedagogia na FAFICA passa a formar profissionais para atuarem na educação infantil, nos anos iniciais do ensino fundamental e na primeira etapa da educação de jovens e adultos, contemplando ainda a gestão escolar, a coordenação 
pedagógica e a possibilidade de atuarem em espaços de educação "não formais" como educadores/as sociais. A docência continua sendo a base do processo formativo, o que implica numa "sólida formação teórica e interdisciplinar, unidade teoria-prática, gestão democrática, compromisso social, trabalho coletivo e interdisciplinar, incorporação da formação continuada e avaliação permanente" (ANFOPE, 2004, p.14).

Portanto, o curso de Pedagogia na FAFICA inscreve-se na dinâmica de impasses, debates, embates, resistência e crises pelos quais a trajetória formativa do/a pedagogo/a vem se consubstanciando em nosso país. Conforme Silva (2007, p. 224), em síntese,

[...] a reformulação desse curso parte das tensões nacionais - debate entre o MEC/CNE e o movimento dos(as) profissionais da educação em torno do modelo de formação (Instrumentalista e Emancipador) - como também das que dinamizam o cenário local da instituição - os diversos interesses dos sujeitos da comunidade acadêmica da Faculdade - "tinha professor que achava que a legislação tinha que ser cumprida e aqueles que defendiam a discussão do movimento dos educadores" (ECG).

Sem perder de vista o diálogo com as determinações oficiais sobre o curso de Pedagogia, na FAFICA as reformulações pelas quais tem passado o processo formativo do/a pedagogo/a trazem as marcas das demandas locais e as proposições do movimento dos/as educadores/as em suas entidades representativas.

\section{RAZÕES E EXPECTATIVAS PELA ESCOLHA DA PROFISSÃO DOCENTE E PELA LICENCIATURA EM PEDAGOGIA}

$\mathrm{Na}$ análise e na discussão dos dados procuramos, inicialmente, traçar o perfil dos licenciandos em Pedagogia da FAFICA quanto ao estágio formativo, ao gênero, à idade, ao contexto profissional, às escolas em que estudaram, à renda familiar e à escolaridade dos pais e das mães. Em seguida, discutimos as razões que os levaram à escolha pelo curso de Pedagogia e suas expectativas em relação ao exercício profissional docente.

\section{PERFIL DOS/AS LICENCIANDOS/AS EM PEDAGOGIA DA FAFICA}

Os/as 153 discentes (Identificados pela letra $\mathrm{P}=$ Pedagogia, seguida do período $2^{\circ}, 4^{\circ}, 6^{\circ}$ ou $8^{\circ}$ e do número do entrevistado) que responderam ao questionário estão situados em diferentes estágios do processo formativo, sendo $22,9 \%$ deles estudantes do segundo período, $36,6 \%$ do quarto, $22,2 \%$ do sexto e $18,3 \%$ do oitavo. Todos/as estudam durante o período noturno.

Quanto ao gênero dos/as licenciando/as de Pedagogia da FAFICA, 90,1\% são do sexo feminino. Segundo Apple (1998, p.15), a feminização do magistério está intrinsecamente relacionada "a um processo de trabalho articulado às mudanças, ao longo do tempo, na divisão sexual do trabalho e nas relações patriarcais e de classe." A questão de gênero ainda é um fator interveniente nas motivações e na escolha pela profissão docente.

Quanto à idade, a maioria, 62,1\%, tem uma faixa etária compreendida entre 18 e 23 anos, o que mostra a tendência de ingresso no ensino superior de uma demanda cada vez mais jovem. Entre 25 e 29 anos, situa-se o percentual de 17,9\%; entre 30 e 39 anos, 13,1\%; de 40 a 49 anos, 5,5\% e, acima de 50 anos, 1,4\%. Para Gatti (2010), a faixa etária ideal para o ingresso na formação docente é de 18 a 24 anos, como é o caso da maioria dos/as licenciandos/as da FAFICA, "uma vez que estas [características, entre as quais idade, sexo, trajetória escolar, faixa salarial familiar etc.] têm peso sobre as aprendizagens e seus desdobramentos na atuação profissional" (GATTI, 2010, p. 1.361). 


\section{autêntica}

Foi ainda objeto de nossos questionamentos a trajetória escolar dos/as licenciandos/as. Conforme tabela que se segue, a maioria vivenciou seu processo formativo na educação básica em escolas públicas.

TABELA 1

ESCOLA EM QUE CURSARAM A EDUCAÇÃo BÁSICA

\begin{tabular}{|c|c|c|}
\hline \multirow{2}{*}{ ETAPA FORMATIVA } & \multicolumn{2}{|c|}{ ESCOLA } \\
\cline { 2 - 3 } & PÚBLICA & PRIVADA \\
\hline Educação infantil & $64,9 \%$ & $35,1 \%$ \\
\hline Ensino fundamental (anos iniciais) & $83,2 \%$ & $16,8 \%$ \\
\hline Ensino fundamental (anos finais) & $88,2 \%$ & $11,8 \%$ \\
\hline Ensino médio & $80,4 \%$ & $19,6 \%$ \\
\hline
\end{tabular}

O Exame Nacional do Ensino Médio (ENEM), ainda que se trate da totalidade dos resultados sem fazer uma relação direta com os/as discentes que estão nas licenciaturas, tem mostrado que a média obtida por alunos/ as provenientes da escola pública tem ficado abaixo de $40 \%$ de acertos. Esse fato, pontuado por Gatti (2010), preocupa-nos, visto que os/as licenciandos/as de Pedagogia, em sua maioria, têm sua formação escolar básica feita em instituições públicas. Isso mostra que "[...] a escolaridade anterior realizada em escola pública evidencia grandes carências nos domínios de conhecimentos básicos. É com esse cabedal que a maioria dos licenciandos adentra nos cursos de formação de professores" (GATTI, 2010, p. 1.364).

No que diz respeito à formação que tiveram no ensino médio, 51,7\% deles fizeram estudos gerais, 45\% cursaram o magistério/normal médio e 3,5\% fizeram outros cursos. Com isso, se percebe que a demanda para o curso de Pedagogia como uma continuidade natural do normal médio (CRUZ, 2009) vem sofrendo as implicações da própria realidade de diminuição de oferta sofrida pelo normal médio em nossa região.

Quanto à renda familiar, encontramos um dado também observado na pesquisa realizada por Pimenta e Dias (2012): os/as licenciando/as em Pedagogia são pertencentes a camadas sociais de baixo poder aquisitivo. A maioria, $74,6 \%$, dos/as sujeitos da pesquisa tem uma renda familiar de até três salários mínimos, contra 25,4\% com uma faixa de renda média, ou seja, entre três e dez salários mínimos.

A presente pesquisa também teve uma preocupação em analisar, a partir da escolaridade dos pais e das mães, a bagagem familiar cultural dos/as licenciandos/as em Pedagogia. Os dados apontaram que 14,6\% e $10,6 \%$, respectivamente, dos pais e das mães dos/as licenciandos/as não possuem nenhuma escolaridade; $50,3 \%$ dos pais e $40,4 \%$ das mães têm o ensino fundamental I (anos iniciais); 17,2\% dos pais e 22,5\% das mães têm o fundamental II (anos finais); 15,9\% dos pais e 15,9\% das mães têm o ensino médio e apenas $2 \%$ dos pais e $10,6 \%$ das mães possuem ensino superior.

Somados os percentuais de pais e mães analfabetos/as e daqueles/daquelas que apenas cursaram até o ensino fundamental I, chega-se a mais da metade de discentes, "o que denota um claro processo de ascensão desse grupo geracional aos mais altos níveis de formação" (GATTI, 2010, p. 1.364).

Quanto à profissão que exercem os pais, temos um percentual de 30,1\% cuja ocupação profissional é a agricultura e $18,4 \%$ de comerciantes e empresários autônomos. Os demais trabalham nas mais variadas profissões, como servidores públicos, pedreiros, militares e motoristas. Algo que chama a atenção é o fato de menos $1,5 \%$ dos pais ter como atividade profissional a docência. 
Quanto à profissão das mães do/as licenciandos/as de Pedagogia, temos $27 \%$ trabalhando em afazeres domésticos, $21,1 \%$ de agricultoras, $8,8 \%$ de professoras e 4,4\% de atuantes da área educacional, como merendeira, secretária, auxiliar administrativo, bibliotecária e supervisora pedagógica. As demais atuam em diversas áreas, como empregadas domésticas, feirantes, ambulantes, costureiras etc.

Os/as licenciandos/as de Pedagogia também foram indagados/as sobre a sua condição de exercício profissional: $87,6 \%$ afirmam exercerem alguma profissão, entre os quais $67,7 \%$ já exercem a profissão docente e 6,9\% atuam no campo educacional em funções como coordenação pedagógica, gestores e bibliotecários/ as. Os/as demais estão nos mais variados campos profissionais, como comércio, confecções, prestadoras de serviço, segurança pública, artesanato etc.

Dos/as licenciandos/as que atuam na docência, $57 \%$ estão na rede pública. Quanto à etapa de escolarização em que atuam, a maior concentração verifica-se na educação infantil, 42,3\%, e fundamental I, 48,7\%.

Em síntese, os/as licenciandos/as de Pedagogia, de maneira geral, estudam à noite, são do sexo feminino, estão em uma faixa etária de 18 a 23 anos, tiveram sua trajetória escolar anterior ao ingresso no ensino superior feita em instituições públicas, provêm dos cursos de estudos gerais e do magistério/normal médio, são trabalhadores/as com atuação na docência em escolas públicas nas modalidades de educação infantil e ensino fundamental (anos iniciais), possuem uma renda familiar de até três salários mínimos e seus pais e mães, em sua maioria agricultores/as, fizeram até os anos iniciais do ensino fundamental.

\subsection{A ESCOLHA PELO CURSO DE PEDAGOGIA}

A atual configuração do curso de Pedagogia articula "a docência, a gestão educacional e a produção do conhecimento na área da educação" (AGUIAR et. al., 2006, p. 829). Com isso, abre-se um horizonte amplo no que diz respeito à formação e à atuação do profissional formado em Pedagogia.

Quando indagados/as sobre o porquê da escolha do curso de Pedagogia, os/as estudantes apresentam três razões que se destacam: amplas possibilidades do mercado de trabalho e empregabilidade, identificação com o curso e busca de aperfeiçoamento profissional.

A escolha pelo curso atrelada às amplas possibilidades de trabalho e à empregabilidade se expressa nos seguintes depoimentos:

Por ser um curso que oferece muitas oportunidades nas escolas, nas empresas. (P4ㄴㄷㄴ)

Porque abrange outras áreas e não só a sala de aula. (P2³)

Para o mercado de trabalho é o mais que me identifiquei. (P4이)

Porque é uma área que abrange outras profissões. (P8¹25)

Por ser um curso de meu interesse e por ter mais oportunidades de emprego. (P2 $\left.{ }^{\circ} 30\right)$

Porque o curso de Pedagogia abrange várias profissões. (P695)

Porque onde moro é o trabalho que tem. (P466)

Oferece várias opções da área da educação. (P2²3)

Como se pode observar nas falas dos/as licenciando/as, o processo de escolha pela profissão e as amplas possibilidades de inserção no mercado de trabalho estão intrinsecamente ligados, "o que significa que as 


\section{autêntica}

possibilidades de escolha profissional não estão relacionadas somente às características pessoais, mas principalmente ao contexto histórico e ao ambiente sociocultural em que o jovem vive" (GATTI, 2009, p. 9).

O fato de o processo formativo do/a pedagogo/a abrir oportunidades de atuação profissional em espaços escolares para além da docência e também em não escolares aparece como um dos elementos definidores da escolha e das expectativas pelo curso de Pedagogia.

No tocante à identificação com o curso de Pedagogia como determinante no ingresso no ensino superior, vejamos as seguintes respostas:

Porque gosto dessa profissão. (P2³5)

Porque me identifico com a docência. (P8¹38)

Porque me identifico com esse curso por gostar muito de criança. (P8¹52)

Me identifico bastante e será valioso na carreira escolhida. (P6¹11)

Esse curso sempre me chamou a atenção e, por me identificar muito e combinar comigo, resolvi cursá-lo. (P461)

Constata-se que a escolha pelo curso de Pedagogia está atrelada a questões subjetivas de identificação pessoal, seja com a área, seja com o gosto por lidar com crianças. Entretanto, ainda temos que considerar a forte influência de fatores contextuais, como é o caso da empregabilidade, do salário e das condições financeiras que impossibilitam pagar cursos mais caros.

A busca por aperfeiçoamento profissional é explicada pelo fato de muitos estudantes já atuarem na docência ou serem oriundos do curso normal médio e, por isso, entenderem que o curso de Pedagogia seria a possibilidade de adquirir esse aperfeiçoamento. Aliás, essa foi a resposta que mais se evidenciou entre as demais categorias em análise. Foram cerca de 50 entre as 153 respostas. Vejamos algumas delas:

Por estar atuando e precisar da teoria para me orientar e ajudar na prática. (P46ㄱ

Para um aperfeiçoamento e direcionamento da profissão escolhida. (P2 1$)$

Para me aperfeiçoar na área em que atuo. (P4 $\left.{ }^{\circ} 65\right)$

Para completar meu sonho e adquirir mais conhecimento. (P6 97 )

Porque quero expandir meus conhecimentos pedagógicos. (P2 $\left.{ }^{\circ} 15\right)$

Para engrandecer os meus conhecimentos pedagógicos e profissionais. (P8¹29)

Porque eu tinha terminado o magistério, aí escolhi o curso de Pedagogia, e porque meu trabalho exige. $\left(\mathrm{P} 2^{\circ} 29\right)$

Para que eu possa aperfeiçoar-me e poder trabalhar com os meus discentes futuros. (P8 $\left.{ }^{\circ} 132\right)$

Para adquirir informações teóricas e práticas sobre prática docente. (P6118)

Por necessidade de formação acadêmica, aprofundar meus conhecimentos e melhorar meu salário. (P4ำ

Para poder absorver conhecimentos que podem fazer a associação com minha prática e assim poder melhorá-la. (P695)

A busca por aperfeiçoamento profissional é reveladora de uma preocupação com a qualificação para o exercício da docência. Tais respostas estão aliadas ao fato de $67,7 \%$ dos/as estudantes que responderam ao motivo da escolha de Pedagogia já exercerem a profissão docente. Esse dado é animador na medida em que, mesmo com a educação básica enfrentando duras críticas quanto a sua baixa qualidade, vemos os/as profissionais docentes preocupados/as em melhor qualificar a sua ação. 


\section{autêntica}

Em síntese, podemos afirmar com Gatti $(2009$, p.9) que a escolha profissional

[...]é resultado de fatores extrínsecos e intrínsecos, que se combinam e interagem de diferentes formas, ou seja, o jovem, tendo em vista suas circunstâncias de vida, é envolvido por aspectos situacionais e de sua formação, e, outros, como as perspectivas de empregabilidade, renda, taxa de retorno, status associado à carreira ou vocação, bem como identificação, autoconceito, interesses, habilidades, maturidade, valores, traços de personalidade e expectativas com relação ao futuro.

Pudemos constatar o que nos revela o excerto a cima ao analisarmos as razões e as expectativas que envolvem a escolha pelo curso de Pedagogia. Sendo esse um curso que contempla uma formação em tríplice direção, a saber, a docência, a gestão e a construção de conhecimento no campo educacional, as razões aqui abordadas pela escolha da licenciatura em Pedagogia coadunam-se com esse amplo leque de possibilidades. Outrossim, o fato da maior incidência de respostas estar ligada à busca de qualificação profissional permitenos inferir que essa é uma demanda da sociedade atual que, por força da legislação e/ou do mercado de trabalho, acaba por levar as pessoas a buscar atualização profissional.

\subsection{RAZÕES E EXPECTATIVAS PELA ESCOLHA PROFISSIONAL E ATUAÇÃO DOCENTE}

No que se refere à escolha profissional, identificamos duas categorias: identificação pessoal e profissional e função social da profissão. Os/as estudantes destacaram a identificação com crianças e com o ensino como determinantes para sua escolha, bem como o entendimento de que se trata de uma profissão importante e admirável do ponto de vista social e de sua contribuição para a transformação da sociedade e dos/ as cidadãos/ãs.

Na primeira categoria -identificação pessoal e profissional -, observamos nas justificativas dos/as estudantes que o fato de gostar e de se identificar com crianças, assim como as lembranças das brincadeiras da infância, foram determinantes para sua escolha profissional, como ilustram as falas a seguir:

Pelo fato de me identificar com crianças e por gostar de exercer a profissão. (P479)

Por gostar de trabalhar com crianças. (P6 $\left.{ }^{\circ} 111\right)$

Porque gosto de crianças. (P28)

Porque me identifico com essa profissão, gosto de crianças e tenho muita paciência. (P2¹3)

Uma profissão que sempre gostei, desde minhas brincadeiras de criança até os dias de hoje. (P467)

Porque desde criança admirava os meus professores e brincava de escola com amigos, aí surgiu a vontade de lecionar. (P8¹49)

Porque me identifico com crianças. (P8¹53)

Por ser uma vontade desde criança. (P2 $\left.{ }^{\circ} 18\right)$

Porque sempre me identifiquei com essa profissão, sempre sonhei em ser professora. (P6 $\left.{ }^{\circ} 127\right)$

Porque desde criança me identifico com essa área. (P6¹120)

Porque desde pequena esse sempre foi o meu sonho, passar conhecimento aos alunos, e sem contar que amo trabalhar com crianças. (P8¹33)

Porque através do magistério comecei a gostar mais ainda e me identifico muito com criança. (P2³1) Porque adoro lidar com crianças. (P2 $\left.{ }^{\circ} 22\right)$

Porque gosto de criança e de ensinar. (P4ำ

Porque gosto de ser professora, me identifico muito e adoro criança, meu sonho era ser professora. (P8०147) 


\section{autêntica}

Admitimos que gostar é um passo importante para o exercício profissional, mas não é suficiente. Conforme Santiago (2006, p.114), "a natureza do magistério solicita ao profissional a atitude de gostar e de respeitar as pessoas; solicita, ao mesmo tempo, conhecimento, criticidade e generosidade que deem sustentação aos processos de intervenção pedagógica e social." Desse modo, entendemos que o gostar de crianças é um elemento importante para o trabalho do/a professor/a, mas deve estar inscrito em uma perspectiva política e epistemológica que contribua para o seu exercício profissional e para o modo como ele lida com os/as discentes.

Contudo, não podemos deixar de situar que o gostar de crianças faz parte de uma construção social e histórica na qual se associa a docência à maternidade, ao cuidar, o que, consequentemente, leva à questão da feminização do magistério. Como vimos, no curso de Pedagogia há um predomínio do gênero feminino. Inferimos que os sentidos atribuídos ao pedagogo e à sua profissão estão ancorados em uma perspectiva tradicional, social e cultural. Compreender a docência desse modo é concebê-la de maneira romantizada e, ao admitir que o gostar é suficiente para o exercício do magistério, admite-se também que a docência não é uma profissão, mas um sacerdócio, uma vocação, um dom divino.

No que se refere à função social da profissão docente, os estudantes afirmam que a docência é uma profissão muito importante, capaz de transformar a sociedade e os/as cidadãos/ãs. Vejamos:

Porque acho uma profissão digna. (P467)

Porque acredito que a educação pode contribuir para a formação de um cidadão crítico e ativo. (P698) Porque acredito na força transformadora e em uma educação popular para todos. (P6¹12)

Porque é uma profissão muito importante para a humanidade. É o professor quem nos ensina o que ele sabe e aprende conosco. (P2 $\left.{ }^{\circ} 17\right)$

Porque acredito que ainda haverá mudanças na educação do nosso país. (P8¹46)

Escolhi a docência pois acredito que a educação é transformadora. (P480)

Porque é uma profissão muito bonita. (P2³0)

Porque acho uma profissão de muita importância e vejo que hoje em dia ninguém dá muito valor. (P4 $\left.{ }^{\circ} 70\right)$

Porque acho muito importante o papel do educador. (P8¹26)

Achava uma profissão muito bela. (P6 92 )

Porque é uma profissão importante para o futuro do nosso Brasil. (P2²0)

Nos depoimentos percebemos que os/as estudantes afirmam que é uma profissão "bonita", “bela", capaz de promover a "transformação" da sociedade e das pessoas. Eles/as veem na profissão um trabalho fundamental para a formação dos indivíduos e a possibilidade de ensinar o outro, de transformá-lo, transformando assim a sociedade na qual se está inserido. Esses dados também podem ser vistos em Gatti (2009).

Para Gatti (2009, p. 39), “ uma característica forte da docência está na dependência do outro para se alcançar suas metas profissionais e, nesse sentido, a realização pessoal do professor depende também do 'sucesso' do aluno. Quando isso se realiza, o trabalho torna-se, de fato, gratificante [...]".

Os/as estudantes também destacam a possibilidade de contribuição do seu trabalho para a transformação da educação, acreditando na possibilidade de fazer a diferença através de uma prática pedagógica comprometida com essa transformação e com a formação de cidadãos/ãs críticos/as e reflexivos/as, como mostram as falas que se seguem: 


\section{autêntica}

Porque é uma profissão que me identifico, na qual pretendo contribuir para a formação de muitas crianças. (P4 $\left.{ }^{\circ} 75\right)$

É uma forma de descobrir, de ajudar o aluno, a pessoa como ser humano. (P2 ${ }^{\circ} 30$ )

Gosto da profissão, me identifico e sempre tive a vontade de fazer com que a educação comece a mudar, fazendo diferente. (P4 $\left.{ }^{\circ} 76\right)$

Para contribuir com a emancipação de sujeitos na construção do conhecimento. (P6 $\left.{ }^{\circ} 116\right)$

Pelo motivo de querer dar minha contribuição para a formação de cidadãos. (P8¹40)

Porque quero contribuir para o crescimento das pessoas. (P8¹46)

Para que eu pudesse ter uma chance de mudar, de fazer a diferença para agir com justiça e prudência no ambiente escolar. (P6¹22)

As falas ilustram a compreensão que os/as estudantes possuem de seu papel e são reveladoras de uma visão heroica. Eles/as se percebem como possuidores de uma capacidade de fazer a diferença e de transformar a educação através do seu trabalho. Consideramos que acreditar que a mudança é possível e ter motivação para o desenvolvimento de seu trabalho é fundamental para uma educação de qualidade, mas é preciso ainda compreender que a educação não é neutra.

Nesse sentido, Freire (1996, p.38) nos diz que:

Outro saber de que não posso duvidar um momento sequer na minha prática educativo-crítica é o de que, como experiência especificamente humana, a educação é uma forma de intervenção no mundo. Intervenção que além do conhecimento dos conteúdos bem ou mal ensinados e/ou aprendidos implica tanto o esforço de reprodução da ideologia dominante quanto o seu desmascaramento. Dialética e contraditória, não poderia ser a educação só uma ou só a outra dessas coisas. Nem apenas reprodutora nem apenas desmascaradora da ideologia dominante. Neutra, "indiferente" a qualquer destas hipóteses, a da reprodução da ideologia dominante ou a de sua contestação, a educação jamais foi, é, ou pode ser. É um erro decretá-la como tarefa apenas reprodutora da ideologia dominante como erro é tomá-la como uma força de desocultação da realidade, a atuar livremente, sem obstáculos e duras dificuldades. Erros que implicam diretamente visões defeituosas da História e da consciência. [Grifos do autor]

Diante das reflexões do autor, compreendemos que a educação não é neutra e que pode tanto transformar a sociedade como reproduzir a ideologia dominante. Portanto, o educador, em sua prática educativa-reflexiva, deve saber que educar não é um processo neutro, pois envolve posicionamentos políticos e epistemológicos. Gatti (2009) também identificou em sua pesquisa que alguns estudantes veem os professores como super-heróis, responsáveis pelo desenvolvimento e pela salvação da humanidade/sociedade.

A influência familiar, a possibilidade de empregabilidade ou mesmo a viabilidade financeira para fazer o curso de Pedagogia, por ser mais barato em relação a outros cursos de nível superior, também se constituíram como justificativas para a escolha profissional dos estudantes.

Quanto às expectativas em relação ao exercício profissional, apenas 11dos 153estudantes afirmaram não pretender atuar na docência. Contudo, dos 11, 7 pretendem atuar em educação, porém em outras funções, como gestão, coordenação e ainda em secretarias ou assumir concursos públicos em áreas afins. Dos 4 que não pretendem atuar na docência ou em áreas afins com a educação, apenas 2 justificaram. "Depende. Se pagar o mesmo que eu ganho hoje sim, caso contrário, não", "Não, porque é muito desvalorizado, tanto no reconhecimento quanto na parte financeira." Depreendemos que a maioria dos/as estudantes pesquisados/ 


\section{autêntica}

as pretendem atuar na docência, alguns deles por identificação desde seu ingresso, outros porque se identificaram ao longo de curso, e outros que já atuam e pretendem permanecer na docência.

Em síntese, podemos afirmar que as razões que levaram os estudantes a escolher a profissão docente são de ordem subjetiva, pois dizem respeito ao processo de identificação pessoal com o trabalho e com o objeto de trabalho, nesse caso, o ser humano, as crianças. E suas expectativas são positivas, uma vez que a maioria dos estudantes pretende exercer a profissão para a qual está sendo formado e possui motivação para realizar uma prática comprometida com a formação das pessoas. Mas há de se considerar que as expectativas dos/ as estudantes em relação ao exercício profissional são de certo modo ingênuas, por não considerarem as questões políticas e epistemológicas que estão em jogo no processo educacional. 


\section{autêntica}

\section{CONSIDERAÇÕES FINAIS}

Ao traçarmos o perfil dos/as estudantes do curso de Pedagogia da FAFICA, observamos que esses os/as licenciandos/as, de maneira geral, estudam à noite, são do sexo feminino, com uma faixa etária entre 18 e 23 anos, e tiveram sua trajetória escolar anterior ao ingresso no ensino superior feita em instituições públicas. Esses estudantes provêm dos cursos de estudos gerais e do magistério/normal médio, são trabalhadores/as com atuação na docência em escolas públicas nas modalidades de educação infantil e ensino fundamental (anos iniciais), possuem uma renda familiar de até três salários mínimos e seus pais e mães são, em grande parte, agricultores/as que cursaram até os anos iniciais do ensino fundamental.

As razões pela escolha do curso foram justificadas em função da identificação com crianças e com a função do ensino, da busca por aperfeiçoamento profissional, uma vez que muitos/as deles/as são oriundos do curso normal médio ou já se encontram atuando na docência, e do amplo horizonte do mercado de trabalho e da possibilidade de empregabilidade. Entre essas categorias, destacamos, por ordem de maior incidência entre as respostas dadas pelos/as estudantes, a busca por qualificação profissional que, podemos inferir, é demandada pela hodierna sociedade que exige profissionais cada vez mais qualificados/as.

Vimos também que as razões aludidas acima no tocante à escolha pelo curso de Pedagogia coadunam-se com a atual configuração dessa licenciatura, que engloba um processo formativo que contempla a docência, a gestão escolar e a produção de conhecimento no campo educacional.

Quanto às razões pela escolha da profissão, foi frequente a referência ao gostar de crianças e à possibilidade transformadora da educação. Os/as estudantes acreditam serem possuidores/as da capacidade de mudar a educação a partir da mudança de seu contexto de trabalho, "fazendo a diferença" através de um comprometimento com a reflexão, a criticidade e a transformação dos indivíduos. Mais de $90 \%$ dos/as estudantes pretendem atuar ou continuar atuando na docência e possuem expectativas muito positivas em relação ao seu exercício profissional. Por fim, o fato de nosso pressuposto inicial - de que também fatores familiares influenciariam na escolha pela docência - quase não ter aparecido como resposta às razões que levam os/ as estudantes a optarem pela profissão docente quando do ingresso no ensino superior apresenta-se como questionamento possibilitador de continuidade desta pesquisa. 


\section{autêntica}

\section{REFERÊNCIAS}

AGUIAR, Márcia Angela da S. et.al. Diretrizes curriculares do curso de pedagogia no Brasil: disputa de projetos no campo da formação do profissional da educação. Educação e Sociedade, Campinas, v. 27, n. 96, p. 819-842, Especial, out. 2006.

ANFOPE. Associação Nacional pela Formação dos Profissionais da Educação. Documento gerador para o XXII Encontro Nacional. Brasília: [s.n.], ago. 2004.

APPLE, Michael. Ensino e trabalho feminino: uma análise comparativa da história e da ideologia. Cadernos de Pesquisa, São Paulo, n. 64, p. 14-23, 1998.

BARDIN, Laurence. Análise de Conteúdo. Lisboa: Edições 70,2010.

BASÍLIO, Márcia Alves Tenório. Curso de Pedagogia: campo semântico das representações sociais dos estudantes. In: MACHADO, Laêda Bezerra. Incursões e investigações em representações sociais e educação. Recife: Ed. da UFPE, 2013. p. 59-71.

BATISTA NETO, José. Valorização do magistério: formação, recrutamento e profissionalização. In: BATISTA NETO, José; SANTIAGO, Eliete (Org.). Formação de professores e prática pedagógica. Recife: Fundação Joaquim Nabuco, Massangana, 2006.

BRASIL. Parecer CNE, n² 252, de 1969.

Constituição (1988). Constituição da República Federativa do Brasil, 1988. Brasília: Senado Federal, Centro Gráfico, 1988. 292 p.

Ministério da Educação. Resolução CNE/CP. n 1, de 15 de maio de 2006. Brasília: MEC, 2006.

Instituto Nacional de Estudos e Pesquisas Educacionais Anísio Teixeira. Censo da Educação Superior 2011 - Resumo Técnico. Brasília, INEP, 2013.

CHIZZOTTI, Antonio. Pesquisa em ciências humanas e sociais. 3. ed. São Paulo: Cortez, 1991.

CRUZ, Gisele Barreto da. 70 anos do curso de Pedagogia no Brasil: uma análise a partir da visão de dezessete pedagogos primordiais. Educação e Sociedade, Campinas, v. 30, n. 109, p. 1187-1205, set./dez., 2009.

DUBAR. Claude. A crise das identidades: a interpretação de uma mutação. Porto: Afrontamento, 2006.

FAFICA. Faculdade de Filosofia Ciência e Letras de Caruaru. Projeto Pedagógico. Curso de Licenciatura em Pedagogia. 2007.

FERREIRA, Naura Syria Carapeto. Diretrizes curriculares para o curso de Pedagogia no Brasil: a gestão da educação como gérmen da formação. Educação e Sociedade, Campinas, v. 27, n. 97, p. 1341-1358, set./dez., 2006. 


\section{autêntica}

FREIRE, Paulo. Pedagogia da Autonomia: saberes necessários à prática educativa. São Paulo: Paz eTerra, 1996.

GATTI, Bernardete A. Atratividade da carreira docente no Brasil: relatório preliminar. São Paulo: Fundação Victor Civita, 2009.

GATTI, Bernardete A. Formação de professores no Brasil: características e problemas. Educação e Sociedade, Campinas, v. 31, n. 113, p. 1355-1379, out./dez. 2010.

INEP Instituto Nacional de Estudos e Pesquisas Educacionais Anísio Teixeira Censo da educação superior: 2011 - resumo técnico. Brasília: INEP, 2013.

MANDÚ, Thamyris Mariana Camarote; AGUIAR, Maria da Conceição Carrilho de. O campo de atuação do pedagogo nas representações sociais de estudantes do Curso de Pedagogia. In: MACHADO, Laêda Bezerra. Incursões e investigações em representações sociais e educação. Recife: Ed. da UFPE, 2013. p. 117-130.

MINAYO, Maria Cecília de Souza. Pesquisa social: teoria, método e criatividade. 26.ed. Petrópolis, RJ: Vozes, 2007, p. 61-78.

NÓVOA, Antônio. Profissão professor. Porto: Porto Editora, 1991.

PIMENTA, Sonia de Almeida; DIAS, Adelaide Alves. Profissionalização docente: expectativas em direção à profissionalização. In: SOUZA, Clarilza Prado de; VILLAS BÔAS, Lúcia Pintor Santiso; TEODORA, Romilda (Orgs.). Representações sociais: políticas educacionais, justiça social e trabalho docente. Curitiba: Champagnat; São Paulo: Fundação Carlos Chagas, 2012. p. 11-132.

POPKEWITZ, Thomas S. Profissionalização e formação de professores: algumas notas sobre a história, ideologia e potencial. In: NÓVOA, Antônio. Os professores e sua formação. 2. Ed. Lisboa: Dom Quixote, 1995.

SANTIAGO, Maria Eliete; NETO, José Batista. Perfil dos professores/as para a atualidade. In: Formação de professores e prática pedagógica. Recife: Fundação Joaquim Nabuco, Massangana, 2006.

SAVIANI, Dermeval. Pedagogia: o espaço da educação na Universidade. Caderno de Pesquisa, São Paulo, v. 37, n. 130, p. 99-134, jan.2007.

SILVA, Janssen Felipe da. Modelos de formação de pedagogos(as)-professores(as) e políticas de avaliação da educação superior: limites e possibilidades no chão da IES. Recife: UFPE, 2007. Tese (Doutorado em Educação) - Programa de Pós-Graduação em Educação, Centro de Educação, Universidade Federal de Pernambuco, Recife, 2007.

TARDIF, Maurice; LESSARD, Claude. O trabalho docente: elementos para uma teoria da docência como profissão de interações humanas. 5.ed. Petrópolis, RJ: Vozes, 2009.

VEIGA, IIma Passos Alencastro; ARAÚJO, José Carlos Souza; KAPUZINIAK, Célia. Docência: uma construção ético-profissional. 2. ed. Campinas, SP: Papirus, 2005. 
